\title{
Using Yoga to Reduce Stress and Bullying Behaviors among Urban Youth
}

\section{Erin E. Centeio, Laurel Whalen, Erica Thomas, Noel Kulik, Nate McCaughtry}

Department of Kinesiology, Health, and Sport Studies, Wayne State University, Detroit, MI, USA

Email: erin.centeio@wayne.edu

How to cite this paper: Centeio, E.E., Whalen, L., Thomas, E., Kulik, N. and McCaughtry, N. (2017) Using Yoga to Reduce Stress and Bullying Behaviors among Urban Youth. Health, 9, 409-424.

https://doi.org/10.4236/health.2017.93029

Received: January 19, 2017

Accepted: March 7, 2017

Published: March 10, 2017

Copyright (c) 2017 by authors and Scientific Research Publishing Inc. This work is licensed under the Creative Commons Attribution International License (CC BY 4.0).

http://creativecommons.org/licenses/by/4.0/

Open Access

\begin{abstract}
Background/Purpose: Obesity and secondary conditions continue to disproportionally affect the health of children living in urban areas. Studies show that a lack of resources and physical activity-unfriendly communities discourage 60 minutes of daily activity, including strengthening exercises, as recommended by the Centers for Disease Control and Prevention. Using Social Ecological theory, the purpose of this study was to examine the multi-level influences of a yoga-based intervention on urban, inner city youth. Method: Using a mixed-methods design, ninety-three $3-5^{\text {th }}$ grade students at five urban elementary schools participated in a ten-week yoga intervention. Analysis/Results: RM-ANOVA results revealed a significant reduction in stress and bullying behaviors among participants, and multiple regression analyses revealed that program attendance, change in stress, and change in yoga enjoyment significantly predicted change in yoga participation outside $\mathrm{PE}$, when controlling for gender and age $F(5,87)=5.36, p<0.01$, adj. $R^{2}=0.19$, but did not have a significant impact on physical activity participation outside of school. Student interviews and non-participant observations revealed strong enjoyment of yoga which led students to report substantial increases in yoga-related activities outside of school. Students also revealed that experience in yoga improved focus, attention, and reduced stress. Conclusions: Through convergence of qualitative and quantitative methods, this study showed a positive relationship between the number of yoga sessions attended (dose), enjoyment of yoga, and participation in yoga outside PE with friends and family. Findings suggest that urban PE should include more individual, non-competitive activities such as yoga, which students find to be stress-relieving, fun, inexpensive and easy to perform at home.
\end{abstract}

\section{Keywords}

Yoga, Physical Education, Stress, Physical Activity, Bullying 


\section{Introduction}

Over the last 30 years, childhood obesity has doubled in youth ages 6 - 11 and quadrupled in those ages 12 - 19 [1] [2]; today nearly one third of the country's young people are overweight or obese [1]. The rate of childhood obesity is even higher among youth living in urban areas [3], ethnic minorities, and those from low-income backgrounds [4], populations that have long suffered from a lack of access to physical activity (PA) and healthy eating resources. The health implications of being overweight or obese are significant; children who maintain an unhealthy weight are more likely to develop serious chronic conditions, suffer from depression, and are more than four times as likely to grow up to be obese adults [5] [6].

By many accounts, a lack of daily PA among youth is a key factor in rising obesity rates [7]. The Youth Risk Behavior Survey [8] monitored youth (Grades 9 12) in a Midwest, inner-city urban area, in part, to assess their physical health. The study found that approximately $24.7 \%$ of youth did not participate in the recommended 60 minutes of PA on a single day, $71.9 \%$ did not engage in PA for at least 60 minutes per day for five days, and as high as $84.2 \%$ were not physically active at least 60 minutes per day all seven days [8]. Other studies have pointed to large declines in PA and significantly increased rates of overweight and obesity among African American females living in inner-cities compared their adolescent peers [9] [10].

Schools are routinely being asked to help address the issue of an increasingly inactive, unhealthy youth population. According to the Institute of Medicine [11], "...because children and adolescents spend so many hours at school, school-related PA must be a large contributor to overall PA among youth." The Centers for Disease Control and Prevention (CDC) has also suggested that the school environment is an ideal one to promote adolescent health.

Schools can create environments supportive of students' efforts to eat healthy and be active by implementing policies and practices that support healthy eating and regular PA and by providing opportunities for students to learn about and practice these behaviors [12].

A range of federal, regional, and local health authorities have pointed to the Comprehensive School Physical Activity Program (CSPAP) [13] as a model to promote PA throughout the school day. While CSPAP suggests integrating PA opportunities before, during, and after school, it also emphasizes quality physical education (PE) as a critical aspect of a successful program. Recent research has suggested that this approach may be a more effective way to increase PA and impact the youth obesity epidemic [13] [14] [15].

Despite this emphasis on increasing activity in the school setting, children across the country are not regularly engaging in PA. According to the Shape of the Nation Report, conducted by SHAPE America and the American Heart Association, only $10 \%$ of states reported offering the recommended 150 minutes of PE per week at the elementary level [16]. In low-income, inner-city schools, this problem is more pronounced given a myriad of sociocultural issues, including an emphasis on 
high-stakes testing that reallocates PE instructional time to core-subjects and testpreparation, and economic stresses that prevent offering high quality $\mathrm{PE}$ and the hiring of certified PE teachers. As a result, the opportunities for student PA, particularly in urban areas, have been disproportionally compromised.

Detroit, Michigan, is a particularly poignant example of the PA inequality for children in urban cities. Nearly $40 \%$ of the city's population lives below the poverty line, including more than $60 \%$ of Detroit children, making it the most impoverished major city in America [17]. Its public school system has been included among the worst in the country [18], largely due to the years of economic decline that the city and its residents have faced. Children who grow up in poverty-stricken neighborhoods and attend inner-city public schools, like in Detroit, are less likely to engage in regular PA due to social factors that pose challenges to access and opportunity including unsafe neighborhoods, lack of greenspace, stressed family lives, and food and housing insecurity. Goodman and colleagues [19] reported that youth from low socioeconomic backgrounds are especially at risk for negative health consequences because of the numerous barriers to health-promoting behaviors, such as PA [19]. Lack of PA has been linked to obesity [20], decline in mental health and increased stress [21].

Research by Mistry and colleagues [22] has indicated that minority, inner-city children experience higher levels of stress than their white, suburban counterparts [22]. As such, children from low socioeconomic backgrounds are also more likely to be affected by stress that negatively impacts behaviors and social skills [22], makes them more likely to be exposed to violence [23], and increase the risk of being a victim of bullying [24].

Although PA is commonly believed to be an effective way to combat stress, this is not always so in the school setting. Given the traditional pedagogy of competitive, sport-based curricula in large PE classes where supervision is often limited, stress and aggression are often exaggerated in the gymnasium [23] [25] [26]. Previous research [25] [27] has suggested that when PE curricula focuses on multi-activity and team-sport models, students are more likely to report increases in bullying, teasing and other aggressive behaviors. Additionally, in an examination of urban youth, Centeio and colleagues [28] found a significant relationship between stress, anger, fighting and bullying behaviors in urban PE. This potentially dangerous environment in the PE classroom is even more significant when we consider how it affects future PA: when students are bullied and experience $\mathrm{PE}$ as stressful and aggressive, it leads to future avoidance of school-based PA opportunities [29].

Recent PE literature has called upon educators to change the "culture of basketball" and focus more on lifetime activities that would be more universally applicable to all students [30]. Ennis suggests that students who participate in PE activities focused on lifetime activities rather than team sports experience more camaraderie and less marginalization during class [27]. Yoga is one example of a lifetime activity that has been increasingly utilized in PE and classroom settings. Yoga is a bone and muscle strengthening activity that is individual, non-resource 
intensive, and can be performed in a variety of settings. A recent review of research on the effects of yoga practice on children produced moderate evidence suggesting benefits for cardiovascular health, physical functioning, and behavior [31]. Yoga research on children also points to improved attention and emotional control [32].

In the school setting, research has shown yoga to provide mental health and physiological benefits, and improve mood and cognition [33]. Chen and colleagues also studied a yoga intervention program in the classroom setting and the practice yielded positive changes in the domains of mental, emotional, physical, and interpersonal growth [34]. Other yoga interventions for students show improvements in emotion regulation, and increased feelings of calmness, relaxation, and self-acceptance [35], improved time on task [36], and improved total mood disturbance and negative affect [37]. In addition, Feldman suggests that children find yoga practice in school to be a calming activity during the stressful school day [38]. Children reported that yoga enabled them to relax their minds and bodies and improved their focus throughout the day. Additional research suggested that mindfulness training can improve academic performance by reducing stress [39] and increasing "time on task" [36].

This study aims to examine the influences of a yoga-based intervention on students in five elementary schools in Detroit. This study was informed by the tenants of Bandura's [40] Social Cognitive Theory (SCT) that suggests, in the context of health promotion, that health behavior is influenced by the interaction of three determinants: personal, environmental, and behavioral factors. In this model, self-efficacy, or "the belief in one's capabilities to organize and execute the courses of action required managing prospective situations" [40], has long been considered the most critical factor in health-related behavior change. Despite this, research conducted among African American youth in inner-cities has suggested social support was a more important predictor of PA [41] [42] [43]. Because youth PA is often determined by the interplay of these personal, environmental, and behavioral factors, this study focused on using SCT to analyze how all three factors were embedded in students' perspectives of yoga practice in a PE setting.

Grounded in the tenants of the SCT, the purpose of this study was to determine how participation in a school-based yoga intervention influenced students in five urban elementary schools. Specifically, we aimed to answer two primary research questions: 1) How does the program impact activity levels (both in continued yoga and general PA) outside of the PE classroom? and 2) How did a yoga intervention program effect stress and bullying in inner city youth?

\section{Methods}

Using a mixed methodological design, 104 youth in Grades $3-5\left(\mathrm{M}_{\text {age }}=9.78, \mathrm{SD}\right.$ $=1.11 ; 82 \%$ African American, $7.6 \%$ Hispanic, $11.4 \%$ other) were recruited from five Detroit elementary schools that were implementing a yoga-based intervention program. The large number of African American youth in this study is rep- 
resentative of the overall population of the city of Detroit. Only those classrooms who participated in the yoga intervention were invited to participate in this study. After parental consent and child assent was obtained, youth participated in a ten-week yoga intervention (one session per week) during PE class. Short surveys were collected from youth at the beginning and end of the yoga program, and students also participated in a short semi-structured interview $(\mathrm{N}=104)$ at the end of their experience. Additionally, research assistants conducted observations $(\mathrm{N}=14)$ of the yoga sessions at least twice at each school throughout the 10-week experience.

\subsection{DKWIO Program}

The Danialle Karmanos' Work It Out (DKWIO) program is a local Detroit, non-profit that, at the time of the study, had been delivering a yoga-based intervention program in Detroit schools for eight years. The DKWIO program is designed to prevent childhood obesity by promoting a healthy mind, body, and spirit through yoga and nutrition programming. Each week (10 weeks total) children are introduced to a unique one-hour formula that includes an introduction, nutritional information, yoga and activities, as well as relaxation and meditation exercises. The program is delivered by volunteer, certified yoga instructors at urban elementary schools as part of students' existing PE programming. By the end of the ten weeks, the DKWIO program goals are that children will have a better understanding of and appreciation for yoga, healthy eating and PA, and that incorporating a practice of yoga will improve students' mental and physical health.

\subsection{Instruments}

Students self-reported gender, age and race. Attendance records for each session were collected by teachers and research assistants. Program attendance was then used as a continuous variable as the number of sessions attended out of ten. Yoga enjoyment was measured by a single item question (e.g. "I enjoy participating in Yoga"), which he students then answered via a 5-point Likert scale ( 1 = strongly disagree, 5 = strongly agree). Yoga participation was measured using a single item question (e.g. "In the last 3 days, how many times did you participate in yoga"). Similarly, participation in PA was also measured using a single question (e.g. "In the last 3 days, how many times did you exercise at a level where you were breathing heavy and sweating"). For both questions, youth were asked to choose an answer on a scale from 0 times to 3 times. These questions were taken and adapted from a valid and reliable PA instrument [44]. Stress in children was measured using the validated Stress in Children Scale [45], which consists of 21 questions that focus on when children feel stressed. Youth were asked to read the question and then circle the answer that best fit their response to the statement using a scale that ranged from 1 (never) to 4 (very often). Measures on this scale included questions like: "I get angry", "I get stomach pains", "When I have a hard time it helps being with my friends". Finally, bullying was measured using the 
Modified Aggression Scale [46]. This scale consists of four questions and youth selected an answer ranging $1-5$ (i.e. $1=$ no opportunity and $5=5$ or more times). Sample questions from the bullying scale included "I teased other students" and "I threatened to hit or hurt another student".

\subsection{Data Analysis}

Using a mixed-methodological design, quantitative and qualitative data were analyzed separately and then both results were examined together to inform the final results. Quantitative data were cleaned and all assumptions were met. Less than $5 \%$ of missing data was observed and items were list-wise deleted. Change variables (post-pre) were calculated for yoga participation, yoga enjoyment, and children's stress. Quantitative data were analyzed using RM-ANOVA and multiple regression analyses in order to answer each research question.

Qualitative data included both observation and interview data. At the end of the ten-week program, youth participants were interviewed $(\mathrm{N}=104$, three declined to participate) to examine their perceptions of the yoga program, its impact on their lives, and their views of the program as a vehicle for health enhancement. The research team developed standardized interview guides including neutral, open-ended questions that were age-appropriate for the 7 - 12-year-old participants. Probes were used to stimulate discussion on specific topics of interest to the research team and allowed for informal interaction between interviewees and researchers. The interviews lasted approximately 10 - 15 minutes, were audio recorded, and transcribed verbatim by the research team for analysis. Data were analyzed through constant comparison and inductive analysis [47] in order to identify themes from the data. Four verifications of trustworthiness were used throughout the research project including: 1) triangulation, 2) peer-debriefing, 3) member checking, and 4) using a rich, thick description [48]. Once trustworthiness of the data was confirmed, coding patterns led to the emergence of themes among youth. These themes are presented below.

\section{Results}

All variables were screened for outliers, missing data, and normality; descriptive statistics and correlational analyses were used to examine variables and relationships (Figure $1 \&$ Table 1). In order to determine if a change in stress and bullying occurred among youth during the DKWIO program (research question two), two repeated measures analysis of variance (RM-ANOVA's) were run. In the first RM-ANOVA, youth stress level pre and post were used along with gender as a within-subjects' variable and age as a covariate. There was a significant reduction in stress from pre-post among males, but not among females $F(1,91)=$ 5.51, $p<0.05, \eta^{2}=0.06$ (see Table $2 \&$ Table 3). A RM-ANOVA was also used to examine a change in bullying over the course of yoga programming. There was a significant decrease in reported bullying among youth, regardless of age and gender $F(1,91)=19.64, p<0.001, \eta^{2}=0.16$ (see Table $2 \&$ Table 3 ).

In order to better understand the program influenced activity levels of youth, 


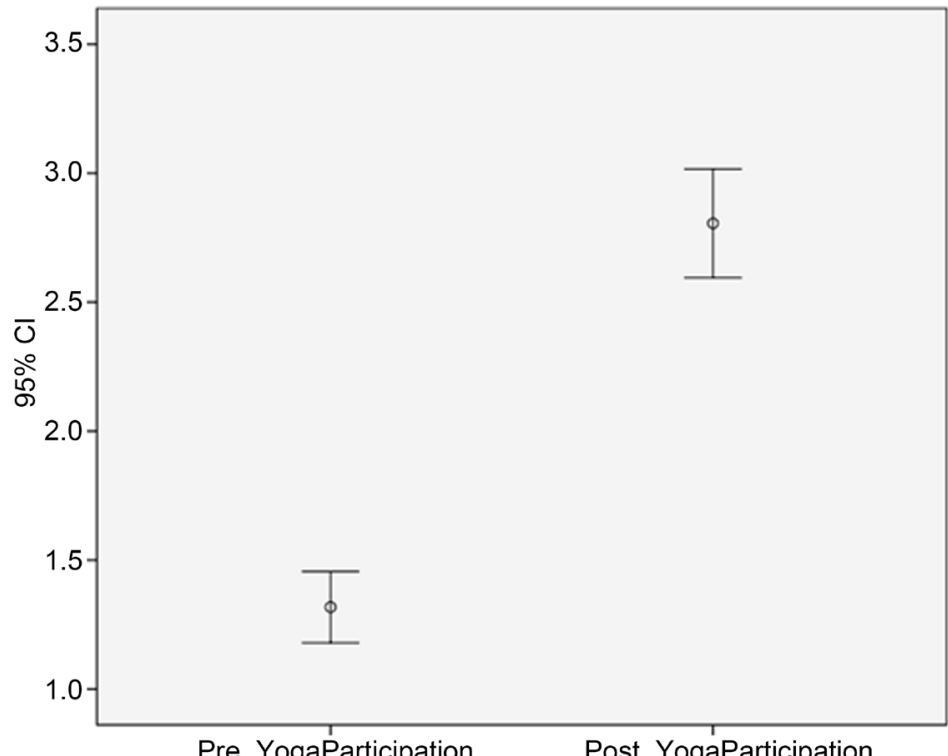

(a)

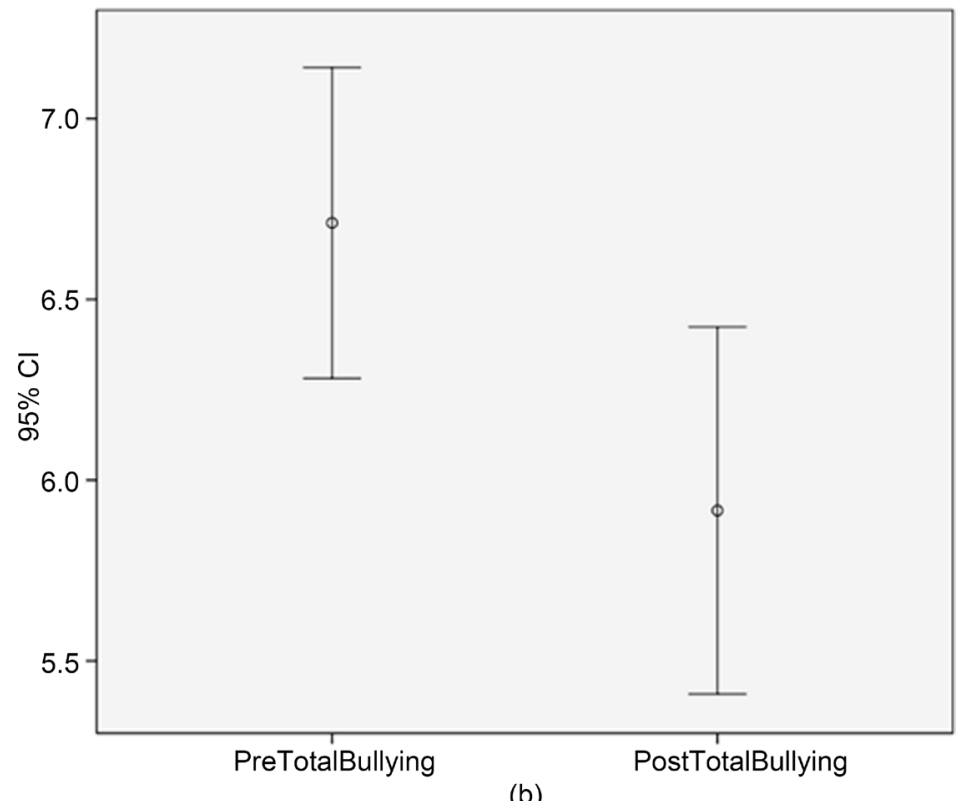

(b)

Figure 1. Error plots for yoga participation and bullying.

Table 1. Correlations of variables.

\begin{tabular}{lcccccccccc}
\hline & 1 & 2 & 3 & 4 & 5 & 6 & 7 & 8 & M & SD \\
\hline 1. Age & 1.00 & & & & & & & 9.78 & 1.11 \\
2. Gender & $-0.28^{* *}$ & 1.00 & & & & & & & 1.54 & 0.50 \\
3. Yoga Attendance & $0.22^{*}$ & 0.12 & 1.00 & & & & & & 8.10 & 2.50 \\
4. $\Delta$ Yoga Participation & -0.05 & 0.10 & $0.29^{* *}$ & 1.00 & & & & & 1.47 & 1.31 \\
5. $\Delta$ Physical Activity & 0.16 & 0.05 & 0.17 & 0.08 & 1.00 & & & & 0.04 & 1.37 \\
6. $\Delta$ Yoga Enjoyment & -0.10 & -0.01 & -0.07 & $0.30^{* *}$ & 0.06 & 1.00 & & & 0.12 & 1.20 \\
7. $\Delta$ Stress & -0.03 & $0.24^{*}$ & -0.03 & 0.19 & 0.05 & 0.04 & 1.00 & -0.44 & 6.41 \\
8. $\Delta$ Bullying & -0.01 & -0.16 & -0.13 & -0.05 & -0.05 & -0.12 & 0.14 & 1.00 & -0.96 & 2.14
\end{tabular}

Note: $p<0.01^{\star *}, p<0.05^{\star}$. 
Table 2. Descriptive statistics.

\begin{tabular}{ccc}
\hline & Mean & Standard Deviation \\
\hline Pre-Stress & 54.17 & 7.61 \\
Male & 53.81 & 7.17 \\
Female & 54.47 & 8.01 \\
Post-Stress & 53.73 & 6.10 \\
Male & 51.73 & 5.27 \\
Female & 55.43 & 6.30 \\
Pre-Bullying & 6.72 & 2.22 \\
Male & 6.79 & 2.25 \\
Female & 6.66 & 2.21 \\
Post-Bullying & 5.76 & 2.33 \\
Male & 6.19 & 2.52 \\
Female & 5.39 & 2.10 \\
\hline
\end{tabular}

Table 3. RM-ANOVA results.

\begin{tabular}{ccccc}
\hline & Pillai's Trace & $F$ & Significance & Partial $\eta^{2}$ \\
\hline \multirow{2}{*}{ Time } & 0.01 & 0.19 & 0.67 & 0.01 \\
Time ${ }^{*}$ Gender & 0.06 & 5.51 & 0.02 & 0.06 \\
& & Sullying & & \\
Time & 0.16 & 19.64 & 0.00 & 0.16 \\
Time* Gender & 0.03 & 2.55 & 0.11 & 0.03 \\
\hline
\end{tabular}

two multiple regression analyses were run. First, controlling for gender and age, change in stress level, program attendance, and PA enjoyment were regressed onto yoga participation outside of PE. Next, controlling for gender and age, change in stress level, program attendance, and PA enjoyment were regressed onto general PA participation (excluding yoga) outside of PE. Results showed that change is stress, PA enjoyment, and program participation were all significant contributors to change in yoga participation outside of the PE setting $F(5$, $87)=5.36, p<0.001$, adj. $R^{2}=0.19$; however, there was no significant change in general level of PA participation $F(5,87)=0.86, p=0.51$, adj. $R^{2}=0.05$ (see Table 4).

After conducting the qualitative analysis, the following three themes emerged from the student interviews and participant observations: 1) students believed that yoga was fun, 2) students believed that they learned to use breathing techniques to help manage stress, anger, and aggression, and help them focus, and 3) students reported increased yoga participation outside of school.

Children reported that they enjoyed doing yoga during PE class because they enjoyed learning new poses and challenging their bodies in ways that many had 
Table 4. Regression analysis results.

\begin{tabular}{|c|c|c|c|c|c|c|}
\hline \multicolumn{7}{|c|}{ Change in Yoga Participation } \\
\hline & $R$ & $R^{2}$ & adj. $R^{2}$ & S.E. & $F$ & Sig. \\
\hline Model 1 & 0.08 & 0.01 & -0.02 & 1.32 & 0.26 & 0.78 \\
\hline Model 2 & 0.49 & 0.24 & 0.19 & 1.18 & 5.36 & 0.00 \\
\hline Model 2 Coefficients & B & S.E. & Beta & $\mathrm{t}$ & Sig. & \\
\hline Gender & -0.19 & 0.27 & -0.07 & -0.71 & 0.48 & \\
\hline Age & -0.14 & 0.12 & -0.12 & -1.16 & 0.25 & \\
\hline Yoga Attendance & 0.21 & 0.06 & 0.39 & 3.90 & 0.00 & \\
\hline$\Delta$ Yoga Enjoyment & 0.25 & 0.11 & 0.22 & 2.36 & 0.02 & \\
\hline$\Delta$ Stress & 0.04 & 0.02 & 0.20 & 2.08 & 0.04 & \\
\hline \multicolumn{7}{|c|}{ Change in Physical Activity } \\
\hline Model 1 & 0.18 & 0.03 & 0.01 & 1.37 & 1.38 & 0.26 \\
\hline Model 2 & 0.22 & 0.05 & -0.01 & 1.38 & 0.86 & 0.51 \\
\hline Model 2 Coefficients & B & S.E. & Beta & $\mathrm{t}$ & Sig. & \\
\hline Gender & 0.12 & 0.33 & 0.04 & 0.38 & 0.71 & \\
\hline Age & 0.21 & 0.14 & 0.17 & 1.46 & 0.15 & \\
\hline Yoga Attendance & 0.05 & 0.07 & 0.08 & 0.73 & 0.47 & \\
\hline$\Delta$ Yoga Enjoyment & 0.11 & 0.12 & 0.10 & 0.92 & 0.36 & \\
\hline$\Delta$ Stress & 0.01 & 0.02 & 0.05 & 0.42 & 0.68 & \\
\hline
\end{tabular}

not done before. When asked what they liked best about the program, many voluntarily named at least one pose that they liked best, including fourth-grader, Shamari (all names are pseudonyms), who said: "I liked learning all different kinds of poses, like cat, tree, and down dog". Josh, a third grader, also talked about enjoying yoga because it brings him "calm and peace" and that "it's fun". Ari, a fifth-grade girl, also suggested that practicing yoga made her feel "happy because I'm building up my muscles so I can be healthy and strong every day".

Several of the students also talked about how they used yoga techniques to help them in other PA activities. Todd, a fourth-grader, said he uses yoga to help him prepare for football: "It keeps you calm and you get to relax and stuff and then it like helps you out, like, football players do it to exercise and stretch and calm them down before games and stuff". Janyelle, a track athlete suggested that the yoga breathing techniques were helpful to her when she was running: "I used them $\cdots$ when I am running and I breathe in and out and I just focus".

Children also reported deriving benefits from yoga participation that they used the breathing techniques to manage stress, control anger and aggression, and improve focus. Students in this study live in depressed areas of Detroit where food and housing insecurity, crime, and high unemployment rates make for particularly stressed families. Children reported that yoga provided them with tools to manage 
stressful life situations. Janyelle said that during yoga she "like [s] that you get to relax your mind and relieve your stress." James, a 10-year-old, also said that yoga was calming for him: "It makes me feel relaxed. Like, it makes all my troubles go away. Especially when I meditate, I think about nothing."

Utilizing the yoga techniques to manage anger and aggression was also a common theme for the young students. The precursors to their anger were typical of elementary students: Jalen, a fifth-grader, got pushed in the mud, Sjonne, a fourth-grader, has a brother who gets on her nerves, and Jamar, a fifth-grader, was getting teased by some of his classmates for getting in trouble and not being permitted to go outside for recess. However, all three of these students pointed to the breathing techniques, in particular, as a mechanism to manage their aggression. Jamar said: "If someone trying to tease me and they be making me mad I just... breathe."

Several of the students also pointed to the improved focus that their yoga practice provided them. Dion, an 11-year-old fifth grader, described how he uses the yoga 'centering' techniques when he's working on particularly difficult school work: "When I think so hard it makes my brain hurt... and I don't want to do my work or nothing, I just breathe in and out and say "I know I can do it." Maya, a 12-year-old, also talked about using the breathing techniques she acquired in yoga to help her manage the stress of standardized testing: "[it helps] because we have to be quiet and we have to be focused and we can't go to the bathroom and we have to stay in one place a long time." Pharrell, a fifth-grader, described the difference between days that they did yoga and those when they didn't: "sometimes when we didn't go to yoga I was, like, getting off task and playing and stuff, but when I start getting to yoga I start realizing I take school more seriously."

Once the children were introduced to yoga in their PE class, most suggested that they practice the techniques at home and with their families. Chris, a third grader, said that he does yoga "on Fridays" and "on the weekends," and most enjoys the meditation practice that he learned. Matt, a fifth-grader, said he does yoga "at home with Grandpa" and Chris also teaches his mom and younger sisters the poses he learns in class.

\section{Discussion}

Through convergence of qualitative and quantitative methods, the purpose of this study was to examine the influences of a yoga-based intervention on urban, inner city youth. Results showed that alongside participating in the DKWIO program, youth, specifically males, were able to decrease their stress levels, while all youth were able to decrease bullying behaviors. Furthermore, change in stress levels, PA enjoyment, and participation in the DKWIO program significantly predicted an increase in the amount of yoga participation outside of school. This is encouraging as those students who feel more stressed and have higher levels of PA enjoyment are more likely to have a greater increase in yoga participation outside of school. This could indicate that youth were learning how to deal with stress 
and choosing yoga to cope. Additionally, students reported enjoying the yoga program and using yoga and mindfulness techniques to help relieve stress and aggression in their lives. Although there is not a significant relationship between participating in the DKWIO program and an increase in moderate-to-vigorous PA outside of school, this is not surprising as yoga itself is not an activity that requires a high intensity of PA nor is it a targeted goal of the intervention.

\subsection{Yoga Programming and Stress}

Youth who grow up in urban environments are more likely to be impacted by stress, negatively affecting social skills and behaviors [22]. Youth who are exposed to extended levels of stress can develop headaches, abdominal pain, high school absenteeism, overeating, and excessive tobacco use [49]. Urban, minority youth tend to be exposed to higher levels of stress than their suburban white counterparts given additional stressors that occur in urban environments (i.e. family stressors, unsafe neighborhoods, fighting pressures, income and food insecurities, etc.) [50]. In this study, male youth showed a reduction in stress over the 10-week period. Although we cannot say for certain the reduction can be attributed directly to the DKWIO program, it is important to understand the implications that stress reduction can have on the overall health of urban students. Chronic or prolonged stress can have a profound impact on youths' physical and mental well-being, leading to illnesses such as depression [51] [52] [53] [54]. By implementing activities such as yoga into the school setting, there is potential to reduce the stress of youth, or at the very least, teach youth healthy strategies to cope with individual stressors.

\subsection{Yoga Programming and Bullying}

Previous studies have shown a relationship between stress in urban students and bullying behaviors and aggression. Students who experienced higher levels of stress were more likely to be aggressive and bully their peers [28]. In recent years, added attention has been given to bullying because of its increasing prevalence among youth and its negative impact on school climate. Bullying occurs on a daily basis with over 3.2 million students reporting they are victims of bullying each year [55] and $71 \%$ of students identifying that bullying is a problem within their school environment [56]. Bullying impacts are particularly pronounced among Black and Latino students who are more likely to suffer academically when bullied [57]. After participating in the DKWIO yoga intervention program, youth were able to decrease both stress and bullying behaviors which could have prolonged effects on the emotional and physical health of urban youth. Additionally, a reduction of bullying behaviors could have an overall impact on the school culture as bullying has been linked to lower academic achievement among students [58].

\subsection{Yoga Participation in the School Environment}

In the urban PE classroom, bullying is of particular concern, given the prolifera- 
tion of competitive, sport-based curricula, and a dearth of appropriate supervision (typically facilitated by overpopulated classes and a lack of certified PE teachers) where aggressive and bullying behaviors have been increasingly problematic. These PE spaces often lead to the marginalization and bullying of students [59]. It has also been shown that students who feel marginalized in the PE setting tend to avoid PA experiences in the future [29]. In this study, it was found that participating in yoga not only reduced stress and bullying behaviors, but also led to an increase in yoga participation outside of the school setting. Many studies have recommended that schools integrate PE programming with more individual, non-competitive activities like yoga [60]. Additionally, given the call to increase PA throughout the school day, it could be beneficial for schools to incorporate yoga activities beyond the PE classroom. Given the potential of utilizing yoga as an effective stress response, a focusing activity, a mechanism to increase PA for historically inactive students, and the potential to reduce stress and bullying behaviors, integrating yoga into a CSPAP (i.e. brain breaks/boosters, hosting a before-after school yoga program) could have a significant impact on not only the well-being of urban youth, but also the climate of the PE classroom and the school as a whole. In a climate where urban students are being asked to improve academic performance, coupled with enhance stressors in the home and school environment, yoga programming has potential to relieve stress, reduce bullying behaviors, and increase PA outside of school.

\subsection{Limitations}

There are several limitations to this research study. First, this is an intervention design without a control group. This, along with a small sample size limits the generalizability of the study. Future research should be conducted that includes a control group and a larger sample size so that changes can be attributed directly to the DKWIO program. Currently, the DKWIO program is a 10 -week yoga intervention. This is a fairly short intervention and if the intervention was longer, there is potential to be greater impacts on the PA and stress levels of youth. Finally, there was a lack of ethnic diversity within this sample population. Although this is representative of an urban youth population, caution should be taken when interpreting the results.

\section{Acknowledgements}

Thank you to the Children Hospital of Michigan Foundation for the generous funding of this research and to Danialle Karmanos Work It Out Program (DKWIO).

\section{References}

[1] Ogden, C.L., Carroll, M.D., Kit, B.K. and Flegal, K.M. (2014) Prevalence of Childhood and Adult Obesity in the United States, 2011-2012. Journal of American Medical Association, 311, 806-814. https://doi.org/10.1001/jama.2014.732

[2] National Center for Health Statistics (2012) Health, United States, 2011: With Spe- 
cial Features on Socioeconomic Status and Health. U.S. Department of Health and Human Services, Hyattsville.

[3] Pan, L., Freedman, D.S., Sharma, A.J., Castellano-Brown, K., Park, S., Smith, R.B. and Blank, H.M. (2016) Trends in Obesity in the Special Supplemental Nutrition Program for Women, Infants and Children in United States, 2000-2014. Morbidity Mortality Weekly Report, 65, 1256-1260.

https://doi.org/10.15585/mmwr.mm6545a2

[4] Lee, H., Andrew, M., Gebremariam, A., Lumeng, J.C. and Lee, J.M. (2014) Longitudinal Associations between Poverty and Obesity from Birth through Adolescence. American Journal of Public Health, 104, e70-e76. https://doi.org/10.2105/AJPH.2013.301806

[5] Freedman, D.S., Khan, L.K., Serdula, M.K., Dietz, W.H., Srinivasan, S.R. and Berenson, G.S. (2005) The Relation of Childhood BMI to Adult Adiposity: The Bogalusa Heart Study. Pediatrics, 1, 22-27. https://doi.org/10.1542/peds.2004-0220

[6] Herman, K.M., Craig, C.L., Gauvin, L. and Katzmarzyk, P.T. (2009) Tracking of Obesity and Physical Activity from Childhood to Adulthood: The Physical Activity Longitudinal Study. International Journal of Pediatric Obesity, 4, 281-288. https://doi.org/10.3109/17477160802596171

[7] Iannotti, R.J. and Wang, J. (2013) Patterns of Physical Activity, Sedentary Behavior and Diet in U.S. Adolescents. Journal of Adolescent Health, 53, 280-286. https://doi.org/10.1016/j.jadohealth.2013.03.007

[8] Centers for Disease Control and Prevention (2016) Youth Risk Behavior Surveillance System [YRBS]: 2015. https://www.cdc.gov/healthyyouth/data/yrbs/results.htm

[9] Kimm, S.Y.S., Glynn, N.W., Kriska, A.M., Barton, B.A., Kronsberg, S.S., Daniels, S.R., Crawford, P.B., Sabry, Z.I. and Liu, K. (2002) Decline in Physical Activity in Black Girls and White Girls during Adolescence. New England Journal of Medicine, 347, 709-715. https://doi.org/10.1056/NEJMoa003277

[10] Lopez, R.P. and Hynes, H.P. (2006) Obesity, Physical Activity and the Urban Environment: Public Health Research Needs. Environmental Health, 5, 25. https://doi.org/10.1186/1476-069X-5-25

[11] Institute of Medicine (2013) Educating the Student Body: Taking Physical Activity and Physical Education to School. National Academy, Washington DC.

[12] Centers for Disease Control and Prevention (2016) School Health Guidelines. https://www.cdc.gov/healthyschools/npao/strategies.htm

[13] Centers for Disease Control and Prevention (2013) Comprehensive School Physical Activity Programs: A Guide for Schools. U.S. Department of Health and Human Services, Atlanta.

[14] Centeio, E.E., McCaughtry, N., Gutuskey, L., Garn, A., Somers, C., Shen, B., Martin, J. and Kulik, N. (2014) Physical Activity Change through Comprehensive School Physical Activity Programs in Urban Elementary Schools. Journal of Teaching in Physical Education, 33, 573-591. https://doi.org/10.1123/jtpe.2014-0067

[15] Erwin, H., Beighle, A., Carson, R.L. and Castelli, D.M. (2013) Comprehensive School-Based Physical Activity Promotion: A Review. Quest, 65, 412-428. https://doi.org/10.1080/00336297.2013.791872

[16] SHAPE America (2016) Shape of the Nation: Status of Physical Education in the U.S. Author, Reston.

[17] Bouffard, K. (2015) Census Bureau: Detroit is Poorest Big City in U.S. The Detroit News.

http://www.detroitnews.com/story/news/local/michigan/2015/09/16/census-us-uni 
nsured-drops-income-stagnates/32499231/

[18] Lewis, S.D. (2015) Detroit Worst in Math, Reading Scores among Big Cities. The Detroit News.

http://www.detroitnews.com/story/news/local/detroit-city/2015/10/28/national-asse ssment-educational-progress-detroit-math-reading-results/74718372/

[19] Goodman, E., Slap, G.B. and Huang, B. (2003) The Public Health Impact of Socioeconomic Status on Adolescent Depression and Obesity. American Journal of Public Health, 93, 1844-1850. https://doi.org/10.2105/AJPH.93.11.1844

[20] Booth, F.W., Roberts, C.K. and Laye, M.J. (2012) Lack of Exercise Is a Major Cause of Chronic Diseases. Comprehensive Physiology, 2, 1143-1211. https://doi.org/10.1002/cphy.c110025

[21] McPhie, M.L. and Rawana, J.S. (2012) Unravelling the Relation between Physical Activity, Self-Esteem and Depressive Symptoms among Early and Late Adolescents: A Mediation Analysis. Mental Health and Physical Activity, 5, 43-49. https://doi.org/10.1016/j.mhpa.2012.03.003

[22] Mistry, R.S., Biesanz, J.D., Chien, N., Howes, C. and Benner, A.D. (2008) Socioeconomic Status, Parental Investments and the Cognitive and Behavioral Outcomes of Low-Income Children from Immigrant and Native Households. Early Childhood Research Quarterly, 23, 193-212. https://doi.org/10.1016/j.ecresq.2008.01.002

[23] McCaughtry, N., Barnard, S., Martin, J., Shen, B. and Kulinna, P.H. (2006) Teachers' Perspectives on the Challenges of Teaching Physical Education in Urban Schools: The Student Emotional Filter. Research Quarterly for Exercise and Sport, 77, 486-497. https://doi.org/10.1080/02701367.2006.10599383

[24] Bowes, L., Arseneault, L., Maughan, B., Taylor, A., Caspi, A. and Moffitt, T.E. (2009) School, Neighborhood and Family Factors Are Associated with Children's Bullying Involvement: A Nationally Representative Longitudinal Study. Journal of the American Academy of Child and Adolescent Psychiatry, 48, 545-553. https://doi.org/10.1097/CHI.0b013e31819cb017

[25] Kulinna, P.H., Cothran, D.J. and Regualos, R. (2006) Teachers' Reports of Student Misbehavior in Physical Education. Research Quarterly for Exercise and Sport, 77, 32-40. https://doi.org/10.1080/02701367.2006.10599329

[26] Ennis, C.D. (1999) Creating a Culturally Relevant Curriculum for Disengaged Girls. Sport, Education and Society, 4, 31-49. https://doi.org/10.1080/1357332990040103

[27] Ennis, C.D., Solmon, M.A., Satina, B., Loftus, S.J., Mensch, J. and McCauley, M.T. (1999) Creating a Sense of Family in Urban Schools Using the "Sport for Peace" Curriculum. Research Quarterly for Exercise and Sport, 70, 273-285. https://doi.org/10.1080/02701367.1999.10608046

[28] Centeio, E., Whalen, L., Kulik, N., Thomas, E. and McCaughtry, N. (2015) Understanding Stress and Aggression Behaviors among Urban Youth. Journal Yoga Physical Therapy, 5, 187.

[29] Roman, C.G. and Taylor, C.J. (2013) A Multilevel Assessment of School Climate, Bullying Victimization and Physical Activity. Journal of School Health, 83, 400-407. https://doi.org/10.1111/josh.12043

[30] Centers for Disease Control and Prevention (1997) Guidelines for School and Community Programs to Promote Lifelong Physical Activity among Young People. Morbidity Mortality Weekly Report, 46, 1-36.

[31] Galantino, M.L., Galbavy, R. and Quinn, L. (2008) Therapeutic Effects of Yoga for Children: A Systematic Review of the Literature. Pediatric Physical Therapy, 20, 6680. https://doi.org/10.1097/PEP.0b013e31815f1208

[32] Jensen, P.S. and Kenny, D.T. (2004) The Effects of Yoga on the Attention and Beha- 
vior of Boys with Attention-Deficit/Hyperactivity Disorder (ADHD). Journal of Attention Disorders, 7, 205-216. https://doi.org/10.1177/108705470400700403

[33] Ferreira-Vorkapic, C., Feitoza, J.M., Marchioro, M., Simões, J., Kozasa, E. and Telles, S. (2015) Are There Benefits from Teaching Yoga at Schools? A Systematic Review of Randomized Control Trials of Yoga-Based Interventions. Evidence-Based Complementary and Alternative Medicine, 2015, Article ID: 345835. https://doi.org/10.1155/2015/345835

[34] Chen, D.D. and Pauwels, L. (2014) Perceived Benefits of Incorporating Yoga into Classroom Teaching: Assessment of the Effects of "Yoga Tools for Teachers". Advances in Physical Education, 4, 138-148. https://doi.org/10.4236/ape.2014.43018

[35] Broderick, P. and Metz, S. (2009) Learning to BREATHE: A Pilot Trial of a Mindfulness Curriculum for Adolescents. Advances in School Mental Health Promotion, 2, 35-46. https://doi.org/10.1080/1754730X.2009.9715696

[36] Peck, H., Kehle, T., Bray, M. and Theodore, L. (2005) Yoga as an Intervention for Children with Attention Problems. School Psychology Review, 34, 415-424.

[37] Noggle, J., Steiner, N., Minami, T. and Khalsa, S. (2012) Benefits of Yoga for Psychosocial Well-Being in U.S. High School Curriculum: A Preliminary Randomized Controlled Trial. Journal of Developmental and Behavioral Pediatrics, 33, 193-201. https://doi.org/10.1097/DBP.0b013e31824afdc4

[38] Feldman, H. (2005) Teaching Yoga to School-Aged Children: Principles and Personal Experiences. International Journal of Yoga Therapy, 15, 87-95.

[39] Beets, M.W. and Mitchell, E. (2010) Effects of Yoga on Stress, Depression and Health-Related Quality of Life in a Nonclinical, Bi-Ethnic Sample of Adolescents: A Pilot Study. Hispanic Health Care International, 8, 47-53. https://doi.org/10.1891/1540-4153.8.1.47

[40] Bandura, A. (2004) Health Promotion by Social Cognitive Means. Health Education \& Behavior, 31, 143-164. https://doi.org/10.1177/1090198104263660

[41] Whalen, L., McCaughtry, N., Garn, A., Kulik, N., Centeio, E.E., Maljak, K., Kaseta, M., Shen, B. and Martin, J.J. (2016) Why Inner-City High School Students Attend After-School Physical Activity Clubs. Health Education Journal, 75, 639-651. https://doi.org/10.1177/0017896915608885

[42] Garn, A., McCaughtry, N., Kulik, N., Kaszeta, M., Maljak, K., Whalen, L., Shen, B., Martin, J.J. and Fahlman, M. (2014) Successful After-School Physical Activity Clubs in Urban High Schools: Perspectives of Adult Leaders and Student Participants. Journal of Teaching in Physical Education, 33, 112-133. https://doi.org/10.1123/jtpe.2013-0006

[43] Martin, J.J. and McCaughtry, N. (2008) Using Social Cognitive Theory to Predict Physical Activity in Inner-City African American School Children. Journal of Sport \& Exercise Psychology, 30, 378. https://doi.org/10.1123/jsep.30.4.378

[44] Godin, G. and Shephard, R.J. (1985) A Simple Method to Assess Exercise Behavior in the Community. Canadian Journal of Applied Sport Sciences, 10, 141-146.

[45] Osika, W., Friberg, P. and Wahrborg, P. (2007) A New Short Self-Rating Questionnaire to Assess Stress in Children. International Journal of Behavioral Medicine, 14, 108-117. https://doi.org/10.1007/BF03004176

[46] Bosworth, K., Espelage, D.L. and Simon, T.R. (1999) Factors Associated with Bullying Behavior in Middle School Students. The Journal of Early Adolescence, 19, 341 362. https://doi.org/10.1177/0272431699019003003

[47] Corbin, J. and Strauss, A. (2008) Basics of Qualitative Research: Techniques and Procedures for Developing Grounded Theory. Sage, Thousand Oaks. 
https://doi.org/10.4135/9781452230153

[48] Creswell, J.W. (1998) Qualitative Inquiry and Research Design: Choosing among Five Traditions. Sage, Thousand Oaks.

[49] White, L.S. (2012) Reducing Stress in School-Age Girls through Mindful Yoga. Journal of Pediatric Health Care, 26, 45-56. https://doi.org/10.1016/j.pedhc.2011.01.002

[50] Chandra, A. and Batada, A. (2006) Exploring Stress and Coping among Urban African American Adolescents: The Shifting the Lens Study. Preventing Chronic Disease, 3, A40.

[51] Seiffge-Krenke, I. (2000) Causal Links between Stressful Events, Coping Style and Adolescent Symptomatology. Journal of Adolescence, 23, 675-691. https://doi.org/10.1006/jado.2000.0352

[52] Rice, K.G., Herman, M.A. and Petersen, A.C. (1993) Coping with Challenge in Adolescence: A Conceptual Model and Psychoeducational Intervention. Journal of Adolescence, 16, 235-251. https://doi.org/10.1006/jado.1993.1023

[53] McGonagle, K. and Kessler, R. (1990) Chronic Stress, Acute Stress and Depressive Symptoms. American Journal of Community Psychology, 18, 681-706. https://doi.org/10.1007/BF00931237

[54] Kessler, R.C., Berglund, P., Demler, O., Jin, R., Merikangas, K.R. and Walters, E.E. (2005) Lifetime Prevalence and Age-of-Onset Distributions of DSM-IV Disorders in the National Comorbidity Survey Replication. Archives General Psychiatry, 62, 593 602. https://doi.org/10.1001/archpsyc.62.6.593

[55] Cohn, A. and Canter, A. (2014) Bullying: Facts for Schools and Parents. NASP Fact Sheet. http://www.naspcenter.org/factsheets/bullying_fs.html

[56] Nolin, M.J., Davis, E. and Chandler, K. (1996) Student Victimization at School. Journal of School Health, 66, 216-221. https://doi.org/10.1111/j.1746-1561.1996.tb08289.x

[57] Williams, L.M. and Peguero, A.A. (2013) The Impact of School Bullying on Racial/Ethnic Achievement. Race and Social Problems, 5, 296-308. https://doi.org/10.1007/s12552-013-9105-y

[58] Kauts, A. and Sharma, N. (2009) Effect of Yoga on Academic Performance in Relation to Stress. International Journal of Yoga, 2, 39-43. https://doi.org/10.4103/0973-6131.53860

[59] Tischler, A. and McCaughtry, N. (2011) PE Is Not for Me: When Boys Masculinities Are Threatened. Research Quarterly for Exercise and Sport, 82, 37-48. https://doi.org/10.1080/02701367.2011.10599720

[60] McCaughtry, N. (2009) The Child and the Curriculum: Implications of Deweyan Philosophy in the Pursuit of "Cool" Physical Education for Children. In: Housner, L., Metzler, M., Schempp, P. and Templin, T., Eds., Historic Traditions and Future Directions of Research on Teaching and Teacher Education, Fitness Information Technology, West Virginia University, Morgantown, 187-198. 
Submit or recommend next manuscript to SCIRP and we will provide best service for you:

Accepting pre-submission inquiries through Email, Facebook, LinkedIn, Twitter, etc. A wide selection of journals (inclusive of 9 subjects, more than 200 journals)

Providing 24-hour high-quality service

User-friendly online submission system

Fair and swift peer-review system

Efficient typesetting and proofreading procedure

Display of the result of downloads and visits, as well as the number of cited articles Maximum dissemination of your research work

Submit your manuscript at: http://papersubmission.scirp.org/

Or contact health@scirp.org 